\title{
Optimization of Subway Advertising Based on Neural Networks
}

\author{
Ling Sun $\mathbb{D}$, ${ }^{1}$ Yanbin Yang $\mathbb{D},{ }^{1}$ Xuemei Fu $\mathbb{D}^{2},{ }^{2}$ Hao Xu $\mathbb{D}^{3},{ }^{3}$ and Wei Liu $\mathbb{D}^{1}$ \\ ${ }^{1}$ College of Transport and Communications, Shanghai Maritime University, Shanghai 201306, China \\ ${ }^{2}$ School of Management, Shandong University, Shandong 250100, China \\ ${ }^{3}$ CCCC Third Harbor Consultants Co., Ltd., Shanghai 200032, China \\ Correspondence should be addressed to Yanbin Yang; yanbinyang321@163.com and Xuemei Fu; xmfu@sdu.edu.cn
}

Received 30 September 2019; Revised 23 December 2019; Accepted 30 December 2019; Published 10 March 2020

Academic Editor: Eric Florentin

Copyright (c) 2020 Ling Sun et al. This is an open access article distributed under the Creative Commons Attribution License, which permits unrestricted use, distribution, and reproduction in any medium, provided the original work is properly cited.

\begin{abstract}
Subway advertising has become a regular part of our daily lives. Because the target audiences are high-level consumers, subway advertising can promote the return on investment. Such advertising has taken root in various countries and regions. However, a lack of appropriate oversight, a single-track operating mode of subway advertising, and unclear price standards significantly reduced the expected advertising effects and the reasonableness of advertising quotations. The shared biking services have gained a great amount of attention in the past few years. Besides, more citizens get involved in using public transportation, which provides a basis for analyzing subway passenger characteristics. First, we examined the use of shared bikes around subway stations to obtain the information on passengers' age. Then, using daily passenger flow volume, transfer lines, and the original subway advertising quotes, we trained backpropagation neural networks and used the results to provide new quotations. Finally, we combined passenger age structure and different passenger groups' preferences in every station to identify the most suitable advertisement type. Our goal was to make full use of transportation big data to optimize advertising quotations and advertisement selection for subway stations. We also proposed the using of electronic advertising board to help increase the subway advertising profits, decrease the financial pressure of operations, and boost the public transportation development.
\end{abstract}

\section{Introduction}

With the increasing popularity of subway and shared bikes, both of which are commonly agreed to be environmentally friendly transport modes, the "subway+ shared bike" is being chosen by more and more passengers in urban China. By the end of 2016, 30 cities in mainland China have had their own subway systems, with 113 lines and a total length of 4152.8 kilometers. The newest subway systems are in the cities of Fuzhou, Dongguan, Nanning, and Hefei, within which the passenger flow has increased to 16.09 billion, being an annual growth of approximately $16.6 \%$. According to statistics and analysis report of subway rapid transit system of year 2016, 70\% of urban passengers are transported by the subway. Year 2016 also witnessed the rapid development of shared biking services, with total capital financing reaching 7 billion yuan by March 2017. There are more than 30 brands of biking services, among which, Mobike and ofo have completed a new round of financing.
Using the city of Shanghai as an example, shared bikes influence local residents' daily life, to a great extent. At the same time, subway stations have largely extended their life cycles. For 275 out of the 304 subway stations (transfer stations not included), the area of access for bike users exceeds 500 meters. In current Shanghai, this new form of transport mode, i.e., "shared bike plus subway," has significantly reduced the heavy burden on urban transportation, especially for the Middle Ring, which is a ring road between Inner Ring and Outer Ring, covering most downtown areas.

The "shared bike plus subway" pattern has become a first choice for many citizens, which well satisfies their needs by providing a convenient and efficient journey. The 2017 shared bike data travel report for $1 \mathrm{~km}$ around Shanghai Metro, released by DT finance and economics, suggested that the efficiency of "shared bike plus subway" pattern increased to 1.6 times of the original and $80 \%$ of Shanghai subway passengers used shared bikes to travel among their 
work place, home, and subway stations. In addition, shared bike users and subway passengers are reported to have a similar age range. Today's data processing technologies are quite advanced, as such it is feasible to analyze shared bike routes using the Origin-Destination matrix. This analysis helps us better understand passenger characteristics to lay a solid foundation for optimizing subway advertisements.

Subway advertisements are embraced by many advertisers because their placement is associated with a great population flow, fixed target audience, and various advertising forms. Compared with other media, subway advertisements are subject to fewer administrative and legal requirements in China. Hence, subway advertisements are expanding quickly. Regarding the content, the form, or the innovation, the advertisements are full of vitality. However, subway stations are roughly classified into three levels of advertising pricing currently: S level, $\mathrm{A}++$ level, and A level.

Subway passengers mainly include office-goers and white-collar professionals with an advanced educational background, a high level of income, and consumption capability. They are considered to be the target audience for subway advertisements. Among all of the themes, the most attractive subjects are "entertainment," "IT products," "highquality clothing," and "tourism." As subway passengers are rational, not all products are appropriate for being displayed on this platform. If all subway advertisements were designed to gain the attention of subway passengers, they are likely to get better results. Advertising has the potential to be optimized and to be more reasonable in pricing.

1.1. Subway Advisements Are Disconnected to People's Interests, At Least in terms of Content. Advertisers are generally more concerned about the placement and effect of advertisements. They prefer advertising with a high ability to draw attention, high exposure rate, good adaptability, large sizes, with reasonable prices, and in subway stations with large passenger flows. Without further analysis to match products with consumers' preference, advertisers must face high costs and low efficiencies.

1.2. Pricing of Subway Advertisements Is Unreasonable. The subway advertisement pricing is currently only related to the subway station level, the form, and its location. Other attributes are not considered even though they may significantly affect the audience. Unreasonable prices reduce revenue for both advertising agencies and the subway industry. Cost for subway construction is huge for a city. Pricing subway advertisements in a more reasonable manner would help shorten the payback period for the subway construction and increase subway company's revenue. This leads to a solution benefiting everyone.

When it comes to advertising, the dark tunnel walls can be used to display advertising films and public service information to subway riders. This opportunity can increase profits for advertisers and transportation authorities and can attract more state funds (see [1, 2]). In the field of big data, Babar and Arif [3] proposed a smart city architecture, using big data analysis to plan urban facilities. Cano et al. [4] proposed perspectives on big data applications using health information, with the goal of real-time analyses of real-time high-volume and/or complex data from healthcare delivery and citizens' lifestyles. Nachiappan et al. [5] pointed out that replication and erasure coding are the most important data reliability techniques used in cloud storage systems for big data applications.

In the field of backpropagation neural networks, the most important task is solving the issue of multiuser detection in the non-Gaussian noise multipath channel [6]. Hilal solved the issue of multiuser detection in the nonGaussian noise multipath channel. He also paid a close attention to the neural network applications and proposed a new robust neural network detector for multipath impulsive channels. The maximal ratio combining (MRC) technique was adopted to combine the multipath signals. Moreover, he discussed the performance of the proposed multiuser neural network décor-relating detector (NNDD), under class A Middleton model. Furthermore, it showed the performance of the system under power imbalance scenario. They indicated that the proposed NNDD had a magnificent effect on the system performance. The system performance was measured through the bit error rate (BER). Error backpropagation training is a key algorithm to train the neural networks [7]. Prediction accuracy is evaluated using a practical application from the aluminum smelting industry. The dynamic behavior of aluminum smelting makes the particular application well suited to neural network modeling [8]. Yasser et al. [9] proposed the implementation of the SAC (single assignment C) method using a neural network with offset error reduction to control an SISO (single input single output) magnetic levitation system.

Feng et al. [10] considered the primary decisions and activities that arise during backpropagation (BP) neural network model construction, selection, and validation for this novel application. Before using the neural network, training is required until the network fits properly. Many optimized algorithms have been proposed, such as unconstrained optimization [11] and ant colony optimization algorithms [12]. In the field of congestion charge, which means in order to ease the traffic jam the government charges the road users, Eliasson [13] presented a cost-benefit analysis of the Stockholm congestion charging system, using the observed data rather than the model-forecasted data. The most important data sources are travel time and traffic flow. Sachan and Kishor [14] proposed optimum locations for the charging of electric vehicles (EVs); to determine the optimum location, the 24-hour load demand was changed at given junction nodes and the corresponding voltage sensitivity indexes were determined.

A literature review revealed that significant work had been done on advertising optimization by using big data and applying backpropagation neural networks. These have had a significant impact in recent years, and scientists and enterprises have contributed to theory development. However, up to now, only few studies have applied big data and backpropagation neural networks to optimize advertisements in the subway system; there is a particular lack of 
research on pricing using backpropagation neural networks and empirical researches. This provided the research opportunity pursued here. In order to better highlight the characteristics of advertisement in subway system, the author of the paper compared it with other systems. Due to the specialty of public transportation, both subway and bus have fixed stations with fixed passengers. In view of this, subway advertisement will attract more attention from targeted customers. Meanwhile, according to the 2018 Shanghai comprehensive transportation annual report, the transit rides share of subway in 2017 was 54\%, the share of bus was $34 \%$, and the share of taxi was $11 \%$, which means that the subway has a larger volume of passenger flow and mobility than other systems. This substantially increases the effectiveness of subway advertisements. Furthermore, the report mentioned above also revealed that the average passenger volume of subway is 9.69 million trips per day, reaching 10 million trips during working days. In accordance with that, we may state that the subway has become the first public transportation choice of many commuters, resulting in the peak periods of subway. That will require a time-of-use pricing system to make the whole advertising quotation more reasonable.

Therefore, to improve the subway advertisements, we conducted an analysis using "shared bike plus subways" data. The article proposes a novel model to generate the price and types of subway advertisements in different stations and at different times based on neural networks. Backpropagation (BP) neural networks were originally developed by a group of scientists led by Rumelhart and McCelland. These networks are multilayer feedforward, trained using an error inverse propagation algorithm. BP networks learn and store many input-output mapping relationships, without the need to reveal mathematical equations that describe this mapping in advance. Its learning rule involves using the steepest descent method and continuously adjusting the weights and thresholds of the network by backpropagation. This minimizes the sum of squares of the network errors. This BP method is expected to be feasible even with a large dataset.

In fact, there are many elements affecting the price, for example, the age structure of travelers in different time periods and at different stations. These factors are usually ignored by subway advertisement agencies. Subway advertisement prices should follow a specific trend. The neural network has a strong ability to complete a nonlinear simulation, self-organizing, and self-learning, which could be adapted to optimize subway advertisement prices. The subway advertising optimization program is expected to reduce total subway advertising costs, improve advertising effectiveness, increase subway advertising agency revenue, and increase subway system income. All of these benefit livelihoods.

\section{Optimization Methodology and Purpose}

Using big data related to shared bike usage, this paper analyzed a passenger age structure for travelers at different subway stations at different time periods, combined that information with the advertising preferences of different passenger groups, and determined the most suitable advertisement types for different time periods. Finally, this paper proposed the electronic advertising board, which is when one or more advertisers sharing one advertising board during the service time, and alternating between them based on shifts in the target passenger groups. Combined with the number of transfer lines and existing advertising quotation for the stations, and based on the model of neural networks, this study developed a new optimized quotation for each station and new price list to adapt to an optimized scheme for subway advertising.

These following four items summarize the goals of the study:

(1) To develop the advertisement types of catering to consumer preferences and improve advertising effects: subway passenger groups change at different times; as such, the current single-track full-time advertising is no longer the best approach. It is important to update and alternate advertisements as passenger group changes. This electronic advertising board would improve the effective publicity of these ads.

(2) To increase the profit of advertising agencies: based on this study's proposed improvement, it is better to offer specific advertising quotations based on different stations and time periods. This will also improve advertising agencies' profit and increase the advertisements' effects.

(3) To provide a valuable reference for the subway advertising industry: our optimizing analysis can provide a reference for the subway advertising industry in terms of improving advertising reasonableness and offering a high-profit quotation.

(4) To promote the return on investment for subway and benefit the whole society.

\section{Research Idea}

3.1. Data Acquisition. Using shared bike data, this paper analyses the age structures of riders travelling at different time periods in different subway stations. Using existing transfer scale and advertising quotations for each station, this paper optimizes the quotation using a neural networks model. The model accounts for the different preferences of different passenger groups and proposes the best advertisement type for each subway station.

First, Mobike (a shared bike company) usage data were collected for each time period. They include the origin and destination of the used shared bike, specific service time and duration, order id, and bike id. According to a recent industry report released by the Sootoo Research Institute, an authoritative third-party data research institution in China, Mobike has taken $57 \%$ of the market share of shared bikes, and this proportion is still increasing. Thus, the passenger age range of Mobike company is representative to the whole shared bike market. Also, according to the report mentioned above, more than $80 \%$ of the subway users will choose shared 
bikes to travel the first or last $1 \mathrm{~km}$, which means the age structure of these two is similar. Based on Mobike's market share, the overall usage of shared bikes around subway stations was calculated. Second, the passenger age structures for different Shanghai subway stations at different time periods was determined based on the collected data. The formula is as follows:

$$
\frac{P(n \mid A) \times A \times a}{P(n \mid U)}=U_{n}
$$

where $P(n \mid A)$ : different age proportions using the travel mode of "shared bike plus subway;" $P(n \mid U)$ : the ratios of different age groups travelling by subway; A: shared bike usage around different subway stations for different time periods and age groups; $a$ : market share; $U_{n}$ : the passenger flow volumes for different time periods, age groups, and subway stations; and $n$ : different age groups $(n=1$ means passengers below 18 years; $n=2$ means passengers between 18 and 40 years; $n=3$ means passengers between 41 to 50 years; $n=4$ means passengers over 50 years).

Third, based on the data collected through transportation cards, the passenger flow volumes in different time periods of each subway station on the research metro line were obtained. Then, the ratio of subway use to all modes of transportation was calculated to determine the daily overall passenger flow volumes for each subway station.

Fourth, because subway advertising agencies have ranked all the subway stations, the daily advertising costs differ for different stations. This requires further pricing classification. However, there are currently only three levels in the rankings, which is insufficient for classification. As such, to improve the possibility of developing an optimized scheme for the future market, this study introduced the advertising cost per passenger, i.e., the station's total cost, divided by daily overall passenger flow volume.

Fifth, using the calculated subway passenger age proportions and the known preferences of different passenger groups, we calculated the proper advertisement types for each time period. Ultimately, this paper proposes the electronic advertising boards, which is when two or more advertisers share one advertising board during the service period, alternating based on shifts in target passenger groups. In addition, a new quotation scheme is proposed based on the sample of current advertising costs, to adapt to the new subway advertising scheme.

\subsection{Neural Network Training Based on the Backpropagation} Algorithm. In machine learning, specifically deep learning, backpropagation (backprop, BP) is an algorithm widely used in the training of feedforward neural networks for supervised learning; generalizations exist for other artificial neural networks (ANNs) and for functions generally. Backpropagation efficiently computes the gradient of the loss function with respect to the weights of the network for a single input-output example. This makes it feasible to use gradient methods for training multilayer networks, updating weights to minimize loss; commonly one uses gradient descent or variants such as stochastic gradient descent. The backpropagation algorithm works by computing the gradient of the loss function with respect to each weight by the chain rule, iterating backwards one layer at a time from the last layer to avoid redundant calculations of intermediate terms in the chain rule; this is an example of dynamic programming. The term backpropagation strictly refers only to the algorithm for computing the gradient, but it is often used loosely to refer to the entire learning algorithm, also including how the gradient is used, such as by stochastic gradient descent. Backpropagation generalizes the gradient computation in the Delta rule, which is the single-layer version of backpropagation, and is in turn generalized by automatic differentiation, where backpropagation is a special case of reverse accumulation (or "reverse mode"). Backpropagation neural networks contain three or more layers: the input layer, hidden layer, and output layer [15]. The upper layer and lower layer are fully connected, but neurons in the same layer are separated. There is a specific weight between the neurons of the input layer and the neurons in the hidden layers. This is called the signal strength. The hidden layer or the output layer process and integrate the information from the upper layer. In many cases, a threshold will be considered, simulating a nervous system in the real world. In biology, a threshold represents the minimum amount of stimulation to active reactions. The neurons are not active until they reach a threshold value, and the integrated information can be transmitted. Once learning samples are received by the neurons, the valve of the neurons will open, spreading the information to the hidden layers until they reach the output layer. The output layer will generate a response, which is propagated back to all neurons by balancing and adjusting many weights and making uneducated guesses about how to fine-tune them to ensure a bad decision is not made. The key to the $\mathrm{BP}$ algorithm is a negative gradient decline, which identifies the set of weights that minimizes the error in the fastest declining direction. The goal of any supervised learning algorithm is to find a function that best maps a set of inputs to their correct output. The motivation for backpropagation is to train a multilayered neural network such that it can learn the appropriate internal representations to allow it to learn any arbitrary mapping of input to output. Because of the high efficiency of neural networks, it is widely used in various fields, such as water quality assessment [16], fast approximate estimation of data [17], fire sprinkler point data prediction [18], and mechanical performance prediction [19]. The design of the BP neural network is different according to the research content.

The main analysis steps are as follows, which is shown in Figure 1.

(1) Prepare training samples.

(2) Determine the initial parameters of the network.

This involves defining the maximum training parameters, the number of nodes in the hidden layers, learning rates, and the acceptable error after training.

(3) Initialize the weights $w_{i j}$ to random. Initialize the threshold. 


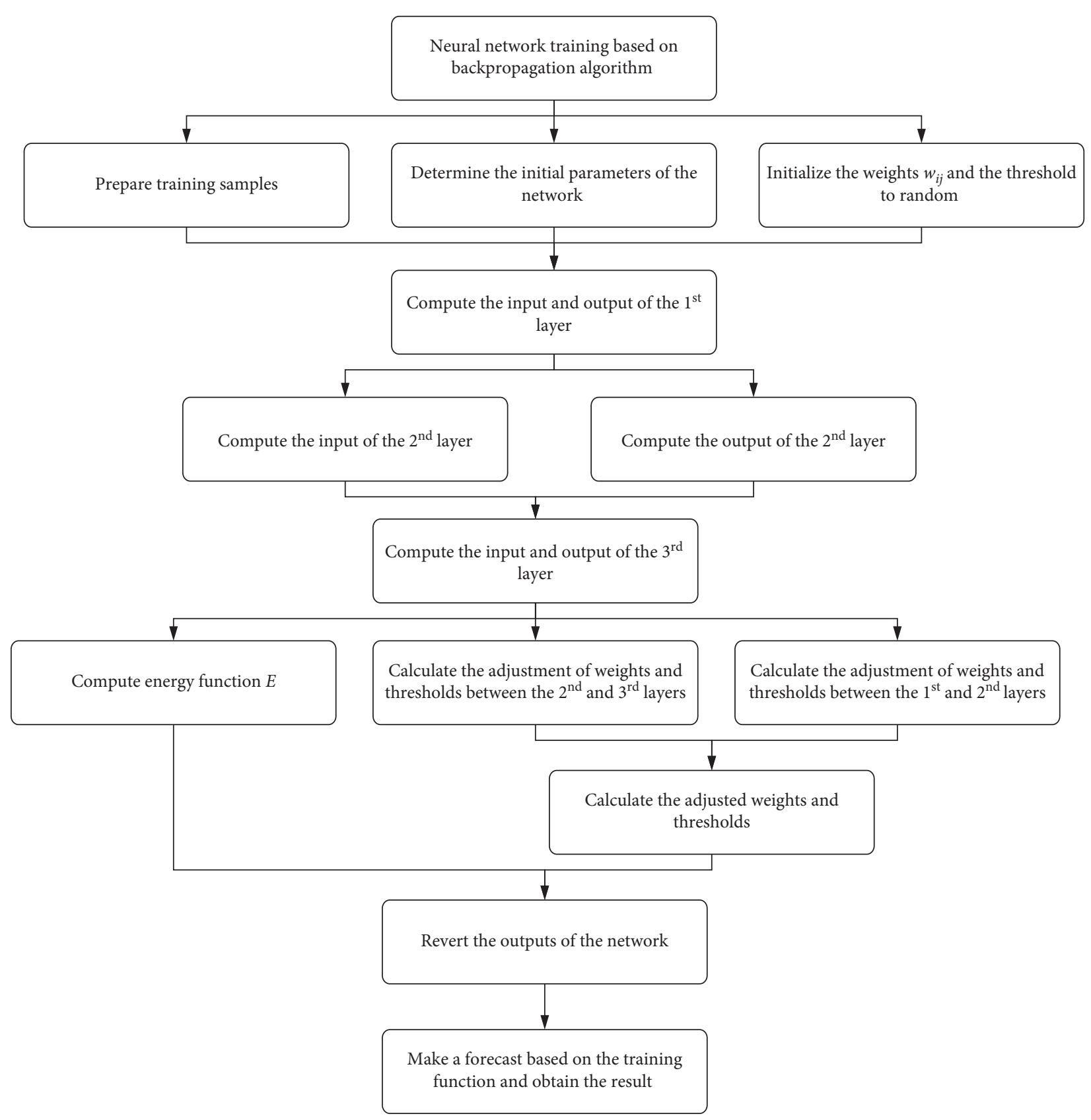

FIGURE 1: Flowchart of analysis step.

Both weights and thresholds are initially set as random values. The weight between the first layer and the second layer is defined as $w_{i j}(t)$; the thresholds of the second layer is defined as $B_{i j}(t)$.

(4) Compute the input and output of the first layer neuron.

Assume that $X$ is the input data. Assume the input and output of the first layer neurons equals the original data. This means that $O_{1}=X$. The input and the output neuron are inconsistent in dimension; as such, the function $[p n, \min p, \max p, t n, \min t$, $\max t]=$ premnmx is applied for normalization.

(5) Compute the input of the second layer.
For the second layer, the input $I_{2}$ is determined by the value of all neurons and thresholds. The function is as follows: $I_{2}=w_{i j} \times X+B_{i j} \times$ ones. In this function, "ones" is the matrix with all elements equaling one.

(6) Compute the output of the neurons in the second layer.

Neurons in the hidden layer or the second layer follow a sigmoid activation function: $f(x)=1 /(1+$ $\left.e^{-x}\right)$. This function computes the output $o$ as $\mathrm{O}_{2}=1 /$ $\left(1+e^{-I_{2}}\right)$.

(7) Compute the input and output of the third layer.

The inputs of the third layer are $I_{3}=w_{j k} \times \mathrm{O}_{2}+$ $B_{j k} \times$ ones; the output of the third layer is $\mathrm{O}_{3}=I_{3}$. 
(8) Compute energy function $E$.

The energy function $E$ is the square sum of error between outputs from the networks and samples; it is designed as a signal to stop the training once acceptable. Suppose the outputs of the networks are $Y$, $E=\Sigma\left(Y-O_{3}\right)^{2}$

(9) Calculate the adjustment of weights and thresholds between the second layer and the third layer.

This is a very key point with respect to BP neural networks; in fact, BP neural networks are based on partial differential:

$$
\begin{aligned}
& \Delta w_{j k}=-\eta \frac{\partial E}{\partial w_{j k}}=-\eta \times\left(Y-O_{3}\right) \times O_{2}, \\
& \Delta B_{j k}=-\eta \frac{\partial E}{\partial B_{j k}}=-\eta \times\left(Y-O_{3}\right) \times \text { ones. }
\end{aligned}
$$

(10) Calculate the adjustment quantity between the first layer and the second layer:

$$
\begin{aligned}
\Delta w_{i j}= & -\eta \frac{\partial E}{\partial w_{i j}}=-\eta \times w_{j k} \times\left(Y-O_{3}\right) \times O_{2} \\
& \times\left(1-O_{2}\right) \times X, \\
\Delta B_{i j}= & \frac{\partial E}{\partial B_{i j}}=-\eta \times w_{j k} \times\left(Y-O_{3}\right) \times O_{2} \\
& \times\left(1-O_{2}\right) \times \text { ones. }
\end{aligned}
$$

(11) Calculate the adjusted weights and thresholds.

Next, we add weights and thresholds and their adjustment quantities. They are weights and thresholds at time $t+1$.

$$
\begin{aligned}
& w_{j k}(t+1)=-\eta \frac{\partial E}{\partial w_{j k}}+w_{j k}(t)=\Delta w_{j k}+w_{j k}(t), \\
& B_{j k}(t+1)=-\eta \frac{\partial E}{\partial B_{j k}}+B_{j k}(t)=\Delta B_{j k}+B_{j k}(t), \\
& w_{i j}(t+1)=-\eta \frac{\partial E}{\partial w_{i j}}+w_{i j}(t)=\Delta w_{i j}+w_{i j}(t), \\
& B_{j i j}(t+1)=-\eta \frac{\partial E}{\partial B_{i j}}+B_{i j}(t)=\Delta B_{i j}+B_{i j}(t) .
\end{aligned}
$$

(12) The outputs of the network should be reverted.

(13) Make a forecast based on the trained function, obtain the result $D_{p}$.

$w_{i j}$ : connection weights between the first layer and the second layer $w_{j k}$ : connection weights between the second layer and the third layer
$B_{i j}$ : neuron thresholds in the second layer

$B_{j k}$ : neuron thresholds in the third layer

$X$ : input sample

$O_{j}$ : the inputs of the second layer $(j=1,2,3, \ldots)$

$I_{j}$ : the outputs of the second layer $(j=1,2,3, \ldots)$

$O_{k}$ : the inputs of the third layer $(k=1,2,3, \ldots)$

$I_{k}$ : the outputs of the third layer $(k=1,2,3, \ldots)$ $p n$ : normalization of $p$

$\min p$ : the minimum element in line $p$

$\max p$ : the maximum element in line $p$

$t n$ : normalization of matrix $t$

$\min t$ : the minimum element in matrix $t$

$\max t$ : the maximum element in matrix $t$

$f(x)$ : activation function

$E$ : energy function

$\eta$ : learning efficiency

$Y$ : the actual output sample

$D_{p}$ : the prediction results

The input of the neural network is the daily passenger flow volume, number of transfer lines, proportion of different age groups, and the original advertisement quotation of different subway stations. The output of the neural network is the optimized cost per passenger.

\section{Case Study}

4.1. Data Filtering. Shanghai Metro Line 1 is one of the city's oldest and busiest metro lines, and it was selected as the case study for this research. Running north-south from Fujin Road to Xinzhuang, Shanghai Metro Line 1 travels across the city through a rich diversity of urban areas. Original data for the study mainly came from the Mobike Technology Company, Shanghai Telecom, Shanghai Metro, and some public websites $[20,21]$. The data were extracted and analyzed using the following steps.

First, Shanghai Metro Line 1 runs from 05:30-23:30 each day. Data from Mobike Company were classified into the following time periods: 5:30-10:00; 10:00-14:30; 14:30-19: 00; and 19:00-23:30. These ranges reflect peak hours. Reports from Sootoo Research Institute showed shared bike users age distribution (Table 1) and Mobike market share, which is $57 \%$. These data provide a solid foundation to estimate the use of shared bikes by different ages of people during different time periods in different subway stations.

Second, by applying Bayes' theorem, this paper estimates the age structure in different time periods at all subway stations along Shanghai Metro Line 1 . The variable $P(n \mid A)$ is obtained from a report on the Shanghai Subway Passenger Flow Analysis, as shown in Table 2. Then, the calculated results are presented in Table 3 (the data were partially adjusted based on the catalog of the sixth census of Shanghai).

Third, we counted the passenger flow and the number of transit lines. The data were provided using data from Shanghai public transportation cards, which excludes cases such as passengers using tickets. Given that $86 \%$ of passengers use the Shanghai public transportation card, the passenger flow in certain subway stations was estimated for this study. 
TABle 1: Age distribution of shared bike users (in percentages).

\begin{tabular}{lcccc}
\hline & $\begin{array}{c}\text { Less than 18 } \\
\text { years old }\end{array}$ & $18 \sim 40$ & $41 \sim 50$ & $\begin{array}{c}\text { More than } \\
50 \text { years old }\end{array}$ \\
\hline $\begin{array}{l}\text { Percentage } \\
(\%)\end{array}$ & 14.10 & 80.00 & 4.70 & 1.20 \\
\hline
\end{tabular}

TABle 2: Age distribution of passengers using the "shared bike plus subway."

\begin{tabular}{lcccc}
\hline Age & $\begin{array}{c}\text { Less than 18 } \\
\text { years old }\end{array}$ & $18 \sim 40$ & $41 \sim 50$ & $\begin{array}{c}\text { More than } \\
50 \text { years old }\end{array}$ \\
\hline Percentage(\%) & 17.42 & 55.89 & 10.89 & 15.80 \\
\hline
\end{tabular}

TABle 3: Age structure of Shanghai subway passenger.

\begin{tabular}{lcccc}
\hline Age & $\begin{array}{c}\text { Less than } 18 \\
\text { years old }\end{array}$ & $18 \sim 40$ & $41 \sim 50$ & $\begin{array}{c}\text { More than } \\
50 \text { years old }\end{array}$ \\
\hline $\begin{array}{l}\text { Percentage } \\
(\%)\end{array}$ & 21.13 & 59.17 & 10.00 & 9.70 \\
\hline
\end{tabular}

Current subway advertising prices were vital data points for neural network learning. There are only three levels (S level, A++ level, and A level). As such, to make the analysis more reasonable, the "cost per passenger" is introduced as the output of the neural network learning. Cost per passenger is calculated as follows, and the results are presented in Table 4.

$$
\text { Cost per passenger }=\frac{\text { Total cost }}{\text { Daily passenger flow }} .
$$

Finally, a survey based on a random sample of two thousand users in Shanghai of China Telecom was conducted to investigate what types of advertising will attract people of different genders and age groups (shown in Figures 2 and 3). Since the Mobike app requires a mobile phone, every Mobike user is assumed to have a mobile phone. Since China Telecom has a certain market share in Shanghai, the data have a solid degree of universal application and can be applied to subway users. Understanding passenger preferences is a key to maximizing advertising utility.

4.2. Data Processing. After grouping the data by age and time period, and combining the weight of the coefficient, all the data can be used as inputs and outputs for the neural network training function. Specifically, the data were listed into 7 groups: the passenger flow at different time periods in different subway stations; the number of transfer lines; and the percentage of passengers in different age groups, at different time periods, and in different subway stations (listed in 4 groups, that is, passengers below 18 years, between 18 and 40 years, between 41 and 50 years, and over 50 years); and the advertisement costs per person.

The original passenger flow data were counted on daily basis. To generate more precise output, flow data were split into several time periods during neural network training. The current price of subway advertisements does not
TABLE 4: Current subway advertising price.

\begin{tabular}{lcc}
\hline Level & Price (yuan/4 weeks) & Daily cost (yuan) \\
\hline S & 482000 & 17214 \\
$\mathrm{~A}++$ & 349340 & 12476 \\
$\mathrm{~A}$ & 172460 & 6159 \\
\hline
\end{tabular}

Source. Shanghai metro light box advertising samples and price list (November 2016).

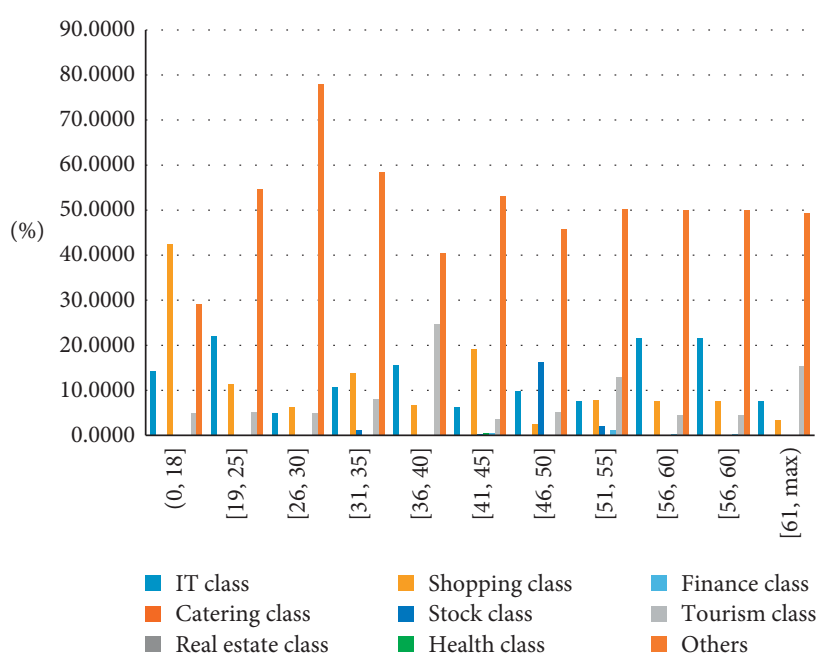

Figure 2: Preferences of females of different ages.

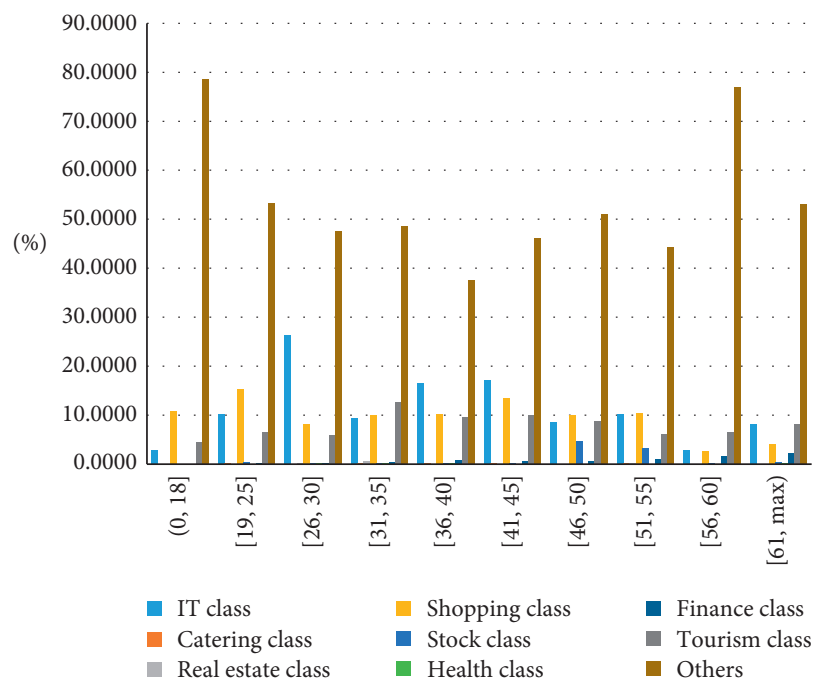

Figure 3: Preferences of male of different ages.

consider passenger age structure; as such, it was treated as an equal value in training function. For forecasting, processed data were input to obtain the age structure at different time periods, so the results could improve the rationality of the pricing.

4.3. Advertisement Quotation Optimization. MATLAB can be used to generate BP Neural Network Training Codes, by typing in the original data and trying the network until the 
degree of fit reaches a certain value. This trained network is then saved for later predictions. The training function was used to obtain the advertising cost per person for each subway station at different time periods. The result was multiplied by the corresponding passenger flow volume to obtain the advertising cost for this time period. Table 5 shows the optimized quotation scheme.

4.4. Advertising Optimization. Based on the preferences of each age bracket, we can get the age structure during different subway stations and time periods (e.g., seen in Table 6).

From an overall perspective, all stations have an average of 14 percentage of passengers under the age of 18 , an average of 80 percentage of passengers at the age of 18-40, 4 percentage of passengers at the age of 40-50, and an average of 2 percentage of passengers over 50 years. Among them, Shanghai South Railway Station accounted for 61 percentage of passengers under the age of 18 in the time period of 19: $00-23: 30$. It is the station with the highest proportion of passengers under the age of 18 at all stations, and the proportion is much higher than the passengers under the age of 18 in other time periods at other stations. There is not much difference in the proportion of passengers of other age groups at each station.

The advertisement types, which contain 14 catalogs, are the same as the data collection of China Telecom. Combined with 2017 Shanghai urban big data active report, released by DT finance and economics, and the proportion of different age groups in various subway stations, the advertisement type of each subway station was obtained and not limited to one type. Table 7 provides the advertisement types.

4.5. Comparison of the Original and New Schemes. The calculations clarify the optimal advertising quotation for each subway station. In contrast to the original quotations (shown in Figures 4 and 5), the new scheme increases the profit.

Comparison of the original and new advertising quotation schemes demonstrates that the new quotation is significantly higher than the original quotation, with striking rises at some subway stations. This outcome is the result of refining the influencing factors of advertising quotations, which significantly differentiates the quotations. As can be seen in Figure 4, for several stations with large growth rates, Shanghai Railway Station and Shanghai South Railway Station are all integrated transportation hubs. Xujiahui and People's Square are the intersections of multiple subway lines, so they all have the characteristics of large traffic. Moreover, the percentage of senior passengers (over 50 years) at these stations is very low, and some are even 0 . Even of the same advertising grade, the overall passenger flow volume impacts those stations' advertising quotation at different time periods, with passenger age structures, and based on the number of transfer lines. For example, although Xinzhuang and Caobao Rd. are of the same advertising grade $(\mathrm{A}++)$ and have the same number of transfer lines, but Xinzhuang has much larger daily overall passenger flow volume than Caobao Rd. As such, the new advertising quotation for Xinzhuang is higher. The stations with Grade
A advertising were also impacted by daily overall passenger flow volumes; the increase in advertising quotation was proportional to the increase in daily overall passenger flow volume. Although the daily advertising costs of most stations have increased, for companies, they only need to purchase advertising services during certain periods of time, so some companies' advertising costs actually have decreased. The highest optimized advertising price cannot exceed the advertising price corresponding to the pedestrian flow when the subway is fully loaded.

The new advertising quotation fully taps the surplus value of customers. Observing the new advertising system as a whole shows that the advertising company will make more profit. Table 8 will show it.

Meanwhile, as for the advertisers, the new advertising scheme will increase the advertising effect. The advertising effect is defined as the number of effective customers that each yuan attracts for an hour. According to data from the China Statistical Yearbook, the average growth rate of per capita health care expenditure of residents in China in the past five years has reached $13 \%$, while the average growth rate of total consumer spending has been $8 \%$. As the health industry is currently booming, the public's attention to this field is increasingly, so the proportion of health advertisements will increase in the future. Therefore, health advertisements are selected for analysis. Take the male aged from 18 to 40 years who are interested in health advertisements as an example. We can find that the advertising effect has increased from 0.0059 to 0.0077 . The effective passenger flow volume here refers to male passenger aged from 18 to 40 years and interested in health advertisements. As the original advertising quotation is designed to cater to everyone, the total advertising quotation is the sum of every station of Shanghai Line 1 in one service day. However, the new advertising scheme has made recommended advertisement type in different time periods for each station, so the total advertising quotation is the value of station that displays health advertisements. The detailed information is listed in Tables 9 and 10.

Due to the lack of certain data, the study could not formally classify the passengers' age structure; however, the results do demonstrate the influence of this variable. For example, Fujin Rd. and North Zhongshan Rd. are very similar, except for the passengers' age structure. However, Fujin Rd. resulted in a lower quotation than North Zhongshan Rd., which also demonstrates that the age structure has a significant influence on the advertising quotation. The number of lines also makes a difference in the new quotation. For example, among the stations classified as Grade S, the advertising quotation for South Huangpi Rd. was significantly lower than the others. This is mainly because South Huangpi Rd. has only one line, whereas the other three stations all have three lines crossing. In this case, while the daily passenger flow volume of South Shaanxi Rd. is smaller than the flow volume of South Huangpi Rd., the final advertising quotation was inversely proportional to daily passenger flow volume based on the impact of the number of transfer lines. Figures 4 and 5 show that the advertising quotations are no longer limited to station grade; 
TABLE 5: Contrast of subway quotation preoptimization and postoptimization.

\begin{tabular}{|c|c|c|c|c|c|c|}
\hline Subway station & Grade & $\begin{array}{l}\text { Advertising cost } \\
\text { preoptimization }\end{array}$ & $\begin{array}{c}\text { Time } \\
\text { period }\end{array}$ & $\begin{array}{l}\text { Advertising cost per } \\
\text { person }\end{array}$ & $\begin{array}{l}\text { Advertising cost } \\
\text { postoptimization }\end{array}$ & Total \\
\hline \multirow{4}{*}{ Fujin rd. } & \multirow{4}{*}{ A } & & 1 & 3.00 & 5686 & \\
\hline & & & 2 & 4.79 & 2568 & \\
\hline & & & 3 & 3.88 & 4452 & \\
\hline & & 6159 & 4 & 4.40 & 3467 & 16173 \\
\hline \multirow{4}{*}{ West Youyi rd. } & \multirow{4}{*}{ A } & & 1 & 3.11 & 5558 & \\
\hline & & & 2 & 4.82 & 2347 & \\
\hline & & & 3 & 4.32 & 3634 & \\
\hline & & 6159 & 4 & 4.44 & 3377 & 14916 \\
\hline \multirow{4}{*}{ Bao'an Highway } & \multirow{4}{*}{ A } & & 1 & 3.57 & 5458 & \\
\hline & & & 2 & 5.15 & 2355 & \\
\hline & & & 3 & 4.50 & 3886 & \\
\hline & & 6159 & 4 & 4.66 & 3563 & 15262 \\
\hline \multirow{4}{*}{ Gongfu Xincun } & \multirow{4}{*}{ A } & & 1 & 2.81 & 6299 & \\
\hline & & & 2 & 4.83 & 3161 & \\
\hline & & & 3 & 3.46 & 5601 & \\
\hline & & 6159 & 4 & 4.42 & 4167 & 19228 \\
\hline \multirow{4}{*}{ Hulan rd. } & \multirow{4}{*}{ A } & & 1 & 3.72 & 5315 & \\
\hline & & & 2 & 5.38 & 2038 & \\
\hline & & & 3 & 4.44 & 3975 & \\
\hline & & 6159 & 4 & 5.23 & 2215 & 13543 \\
\hline \multirow{4}{*}{ Tonghe Xincun } & \multirow{4}{*}{ A } & & 1 & 2.29 & 6648 & \\
\hline & & & 2 & 4.68 & 3512 & \\
\hline & & & 3 & 3.17 & 5961 & \\
\hline & & 6159 & 4 & 3.99 & 4883 & 21004 \\
\hline \multirow{4}{*}{ Gongkang rd. } & \multirow{4}{*}{ A } & & 1 & 2.77 & 6278 & \\
\hline & & & 2 & 4.72 & 3457 & \\
\hline & & & 3 & 3.37 & 5732 & \\
\hline & & 6159 & 4 & 4.20 & 4503 & 19970 \\
\hline \multirow{4}{*}{ Pengpu Xincun } & \multirow{4}{*}{ A } & & 1 & 2.04 & 6558 & \\
\hline & & & 2 & 4.31 & 4510 & \\
\hline & & & 3 & 2.62 & 6436 & \\
\hline & & 6159 & 4 & 3.65 & 5559 & 23063 \\
\hline \multirow{4}{*}{ Wenshui rd. } & & & 1 & 2.82 & 6294 & \\
\hline & A & & 2 & 4.62 & 3643 & \\
\hline & A & & 3 & 3.06 & 6067 & \\
\hline & & 6159 & 4 & 4.89 & 3025 & 19029 \\
\hline & & & 1 & 2.66 & 6402 & \\
\hline & & & 2 & 4.58 & 3754 & \\
\hline Shanghai Circus World & A & & 3 & 3.04 & 6080 & \\
\hline & & 6159 & 4 & 4.44 & 4041 & 20277 \\
\hline & & & 1 & 2.67 & 6396 & \\
\hline & & & 2 & 3.93 & 4894 & \\
\hline Yanchang rd. & A & & 3 & 2.74 & 6346 & \\
\hline & & 6159 & 4 & 4.35 & 4284 & 21920 \\
\hline & & & 1 & 3.44 & 5631 & \\
\hline North 7honoshan rd & A & & 2 & 4.83 & 3228 & \\
\hline North Znongshan ra. & A & & 3 & 3.72 & 5315 & \\
\hline & & 6159 & 4 & 4.84 & 3273 & 17447 \\
\hline & & & 1 & 6.10 & 22991 & \\
\hline & & & 2 & 8.23 & 18775 & \\
\hline Shanghai Railway Station & $\mathrm{A}++$ & & 3 & 6.37 & 22969 & \\
\hline & & 12476 & 4 & 8.97 & 12898 & 77633 \\
\hline & & & 1 & 7.73 & 19932 & \\
\hline & & & 2 & 8.99 & 12190 & \\
\hline Hanzhong rd. & $A++$ & & 3 & 8.03 & 18770 & \\
\hline & & 12476 & 4 & 9.30 & 7103 & 57995 \\
\hline
\end{tabular}


TABle 5: Continued.

\begin{tabular}{|c|c|c|c|c|c|c|}
\hline Subway station & Grade & $\begin{array}{l}\text { Advertising cost } \\
\text { preoptimization }\end{array}$ & $\begin{array}{l}\text { Time } \\
\text { period }\end{array}$ & $\begin{array}{c}\text { Advertising cost per } \\
\text { person }\end{array}$ & $\begin{array}{l}\text { Advertising cost } \\
\text { postoptimization }\end{array}$ & Total \\
\hline \multirow{4}{*}{ Xinzha rd. } & \multirow{4}{*}{$\mathrm{A}$} & & 1 & 4.14 & 4810 & \\
\hline & & & 2 & 5.03 & 2738 & \\
\hline & & & 3 & 3.21 & 5924 & \\
\hline & & 6159 & 4 & 5.14 & 2319 & 15791 \\
\hline \multirow{4}{*}{ People’s Square } & \multirow{4}{*}{$\mathrm{S}$} & & 1 & 7.71 & 20948 & \\
\hline & & & 2 & 8.54 & 16556 & \\
\hline & & & 3 & 6.38 & 23025 & \\
\hline & & 17214 & 4 & 8.60 & 16146 & 76675 \\
\hline \multirow{4}{*}{ South Huangpi rd. } & \multirow{4}{*}{ S } & & 1 & 2.76 & 6473 & \\
\hline & & & 2 & 3.71 & 5357 & \\
\hline & & & 3 & 2.65 & 6413 & \\
\hline & & 17214 & 4 & 4.12 & 4668 & 22911 \\
\hline \multirow{4}{*}{ South Shanxi rd. } & \multirow{4}{*}{ S } & & 1 & 8.71 & 15501 & \\
\hline & & & 2 & 8.96 & 12576 & \\
\hline & & & 3 & 8.34 & 17870 & \\
\hline & & 17214 & 4 & 9.20 & 9201 & 55148 \\
\hline \multirow{4}{*}{ Changshu rd. } & \multirow{4}{*}{$\mathrm{A}++$} & & 1 & 8.02 & 6858 & \\
\hline & & & 2 & 8.70 & 3307 & \\
\hline & & & 3 & 8.08 & 6584 & \\
\hline & & 12476 & 4 & 8.85 & 1954 & 18703 \\
\hline \multirow{4}{*}{ Hengshan rd. } & \multirow{4}{*}{$\mathrm{A}$} & & 1 & 4.42 & 3425 & \\
\hline & & & 2 & 5.42 & 1916 & \\
\hline & & & 3 & 4.68 & 3759 & \\
\hline & & 6159 & 4 & 5.49 & 1493 & 10593 \\
\hline \multirow{4}{*}{ Xujiahui } & \multirow{4}{*}{$\mathrm{S}$} & & 1 & 6.56 & 22848 & \\
\hline & & & 2 & 7.83 & 20477 & \\
\hline & & & 3 & 4.77 & 21951 & \\
\hline & & 17214 & 4 & 8.23 & 18591 & 83867 \\
\hline \multirow{4}{*}{ Shanghai Indoor Stadium } & \multirow{4}{*}{$\mathrm{A}++$} & & 1 & 7.47 & 9314 & \\
\hline & & & 2 & 8.45 & 4596 & \\
\hline & & & 3 & 7.59 & 8639 & \\
\hline & & 12476 & 4 & 8.56 & 3843 & 26392 \\
\hline \multirow{4}{*}{ Caobao rd. } & & & 1 & 6.14 & 12405 & \\
\hline & $A+1$ & & 2 & 7.90 & 7398 & \\
\hline & A++ & & 3 & 6.60 & 11740 & \\
\hline & & 12476 & 4 & 8.29 & 5493 & 37036 \\
\hline & & & 1 & 6.81 & 11169 & \\
\hline Shanghai South Railway & At+ & & 2 & 8.07 & 6745 & \\
\hline Station & A++ & & 3 & 7.02 & 10654 & \\
\hline & & 12476 & 4 & 8.21 & 5435 & 34003 \\
\hline & & & 1 & 3.42 & 5652 & \\
\hline & & & 2 & 4.87 & 3136 & \\
\hline Jinjiang Park & $\mathrm{A}++$ & & 3 & 3.71 & 5303 & \\
\hline & & 12476 & 4 & 4.68 & 3519 & 17610 \\
\hline & & & 1 & 1.79 & 6995 & \\
\hline & & & 2 & 3.38 & 5722 & \\
\hline Lianhua rd. & A & & 3 & 2.02 & 6830 & \\
\hline & & 6159 & 4 & 3.19 & 5947 & 25494 \\
\hline & & & 1 & 3.68 & 5353 & \\
\hline Waihuan Lu & $A$ & & 2 & 5.20 & 2232 & \\
\hline wamuan Lu & A & & 3 & 4.21 & 4419 & \\
\hline & & 6159 & 4 & 5.01 & 2796 & 14800 \\
\hline & & & 1 & 2.17 & 12315 & \\
\hline & & & 2 & 5.38 & 12633 & \\
\hline Xınzhuang & $\mathrm{A}++$ & & 3 & 2.80 & 12547 & \\
\hline & & 12476 & 4 & 5.06 & 12887 & 50382 \\
\hline
\end{tabular}


Table 6: Age structure of Caobao rd. and North Zhongshan rd. at different time periods (percentage).

\begin{tabular}{|c|c|c|c|c|c|}
\hline Subway station & Time period & Age bracket $<18$ & Age bracket $18 \sim 40$ & Age bracket $41 \sim 50$ & Age bracket $>50$ \\
\hline \multirow{4}{*}{ Caobao rd. } & 1 & 0.12 & 0.81 & 0.04 & 0.04 \\
\hline & 2 & 0.13 & 0.78 & 0.06 & 0.03 \\
\hline & 3 & 0.13 & 0.80 & 0.04 & 0.02 \\
\hline & 4 & 0.12 & 0.79 & 0.06 & 0.03 \\
\hline \multirow{4}{*}{ North Zhongshan rd. } & 1 & 0.13 & 0.78 & 0.06 & 0.03 \\
\hline & 2 & 0.20 & 0.80 & 0.00 & 0.00 \\
\hline & 3 & 0.10 & 0.79 & 0.07 & 0.03 \\
\hline & 4 & 0.14 & 0.86 & 0.00 & 0.00 \\
\hline
\end{tabular}

TABle 7: Advertisement types.

\begin{tabular}{|c|c|c|}
\hline $\begin{array}{l}\text { Advertisement } \\
\text { type }\end{array}$ & $\begin{array}{c}\text { Time } \\
\text { period }\end{array}$ & Subway station \\
\hline \multirow{4}{*}{ IT } & 1 & $\begin{array}{c}\text { Gongfu Xincun, Hulan Rd., Wenshui Rd., Hengshan Rd., Xujiahui, Shanghai Indoor Stadium, Jinjiang } \\
\text { Park, Lianhua Rd., Waihuanlu, Xinzhuang }\end{array}$ \\
\hline & 2 & $\begin{array}{l}\text { Fujin Rd., West Youyi Rd., Bao'an Highway, Gongfu Xincun, Hulan Rd., Gongkang Rd., Wenshui Rd., } \\
\text { north Zhongshan Rd., Hanzhong Rd., South Shaanxi Rd., Hengshan Rd., Xujiahui, Waihuanlu, } \\
\text { Xinzhuang }\end{array}$ \\
\hline & 3 & $\begin{array}{l}\text { Fujin Rd., West Youyi Rd., Bao'an Highway, Gongfu Xincun, Hulan Rd., Gongkang Rd., Wenshui Rd., } \\
\text { Hanzhong Rd., South Shaanxi Rd., Hengshan Rd., Xujiahui, Jinjiang Park, Waihuanlu, Xinzhuang }\end{array}$ \\
\hline & 4 & $\begin{array}{c}\text { Bao'an Highway, Gongfu Xincun, Hulan Rd., Gongkang Rd., Pengpu Xincun, Wenshui Rd., Hanzhong } \\
\text { Rd., Xinzha Rd., Hengshan Rd., Xujiahui, Jinjiang Park, Waihuanlu }\end{array}$ \\
\hline \multirow{4}{*}{ Food and Drinks } & 1 & People's Square, Shanghai South Railway Station \\
\hline & 2 & Shanghai Circus World, Shanghai South Railway Station \\
\hline & 3 & Shanghai Railway Station, Shanghai South Railway Station \\
\hline & 4 & Shanghai Circus World, Shanghai Railway Station, People’s Square, Shanghai South Railway Station \\
\hline \multirow{4}{*}{ Real Estate } & 1 & Shanghai South Railway Station \\
\hline & 2 & Shanghai South Railway Station \\
\hline & 3 & Shanghai Railway Station, Shanghai South Railway Station, Jinjiang Park \\
\hline & 4 & Shanghai Railway Station, Shanghai South Railway Station, Jinjiang Park \\
\hline \multirow{5}{*}{ Shopping } & 1 & Hanzhong Rd., People's Square, Caobao Rd. \\
\hline & 2 & $\begin{array}{l}\text { Fujin Rd., West Youyi Rd., Bao'an Highway, Gongfu Xincun, Hulan Rd., Tonghe Xincun, Gongkang Rd., } \\
\text { Pengpu Xincun, Wenshui Rd., Hanzhong Rd., Changshu Rd., Shanghai Indoor Stadium, Caobao Rd., } \\
\text { Lianhua Rd., Waihuanlu, Xinzhuang }\end{array}$ \\
\hline & 3 & $\begin{array}{l}\text { Fujin Rd., West Youyi Rd., Bao’an Highway, Gongfu Xincun, Hulan Rd., Tonghe Xincun, Gongkang Rd., } \\
\text { Pengpu Xincun, Wenshui Rd., Yanchang Rd., Changshu Rd., Xujiahui, Caobao Rd. }\end{array}$ \\
\hline & & Fujin Rd., West Youyi Rd., Bao'an Highway, Gongfu Xincun, Hulan Rd., Tonghe Xincun, Pengpu Xincun, \\
\hline & 4 & $\begin{array}{l}\text { Wenshui Rd., Yanchang Rd., North Zhongshan Rd., Hanzhong Rd., Xinzha Rd., People’s Square, South } \\
\text { Huangpi Rd., South Shaanxi Rd., Changshu Rd., Hengshan Rd., Xujiahui, Shanghai Indoor Stadium, } \\
\text { Caobao Rd., Lianhua Rd., Waihuanlu, Xinzhuang }\end{array}$ \\
\hline \multirow{4}{*}{ Health } & 1 & Tonghe Xincun, Yanchang Rd., Xinzha Rd., South Shanxi Rd., Changshu Rd., Caobao Rd. \\
\hline & 2 & Tonghe Xincun, Yanchang Rd., Changshu Rd., Caobao Rd. \\
\hline & 3 & Tonghe Xincun, Xinzha Rd., Caobao Rd. \\
\hline & 4 & Tonghe Xincun, Changshu Rd., Caobao Rd. \\
\hline \multirow{2}{*}{ Finance } & 3 & \\
\hline & 4 & Xujiahui \\
\hline \multirow{2}{*}{ Finance products } & 1 & Xujiahui \\
\hline & 2 & Xujiahui \\
\hline \multirow{4}{*}{ Travelling } & 1 & Shanghai Railway Station, Shanghai South Railway Station \\
\hline & 2 & Shanghai Railway Station, Shanghai South Railway Station \\
\hline & 3 & Shanghai Railway Station, Shanghai South Railway Station \\
\hline & 4 & Shanghai Railway Station, Shanghai South Railway Station \\
\hline
\end{tabular}


TABle 7: Continued.

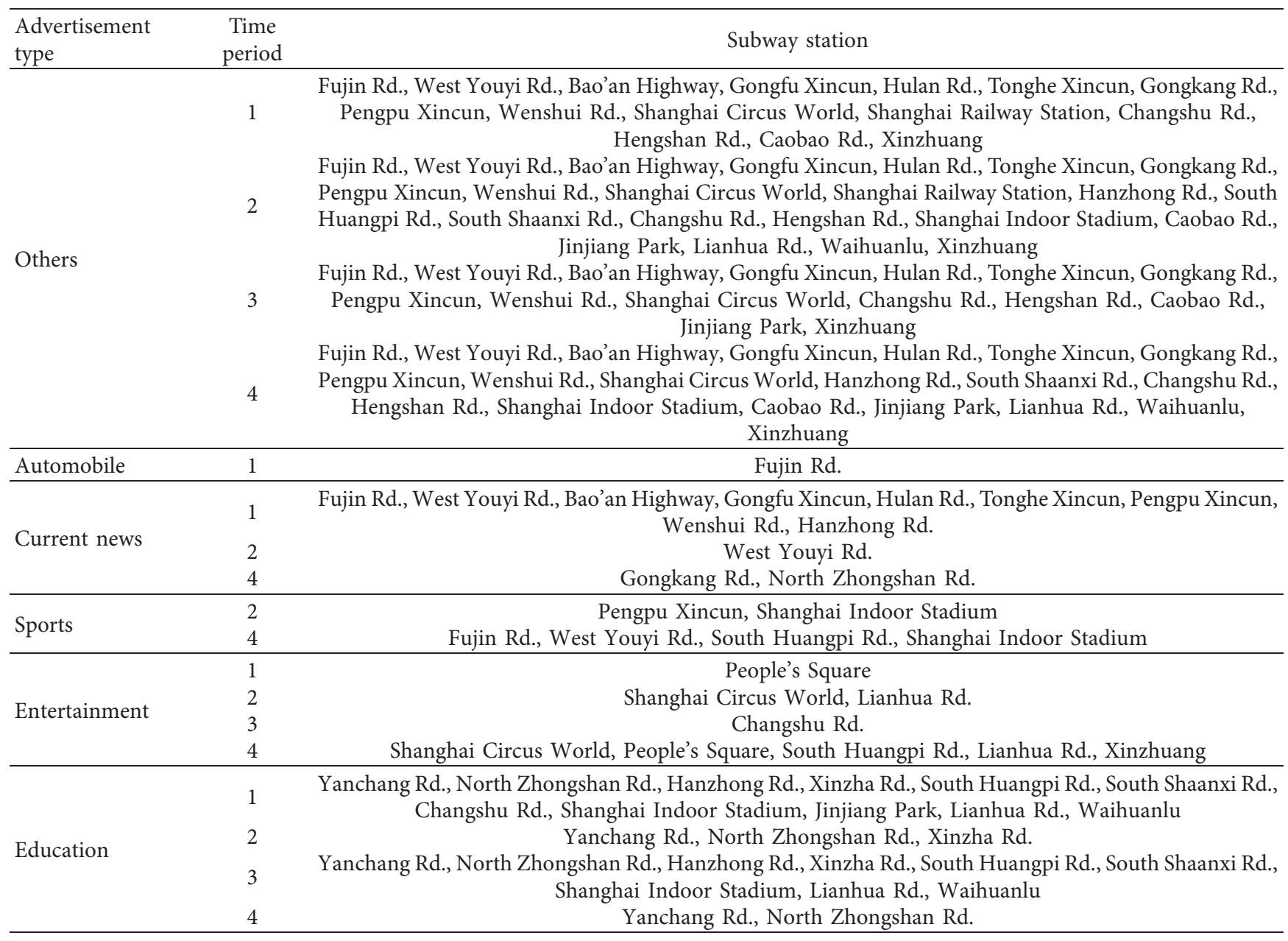

Time period 1 represents the period: 05:30-10:00; time period 2 represents the period: 10:00-14:30; time period 3 represents the period: 14:30-19:00; time period 4 represents the period: 19:00-23:30.

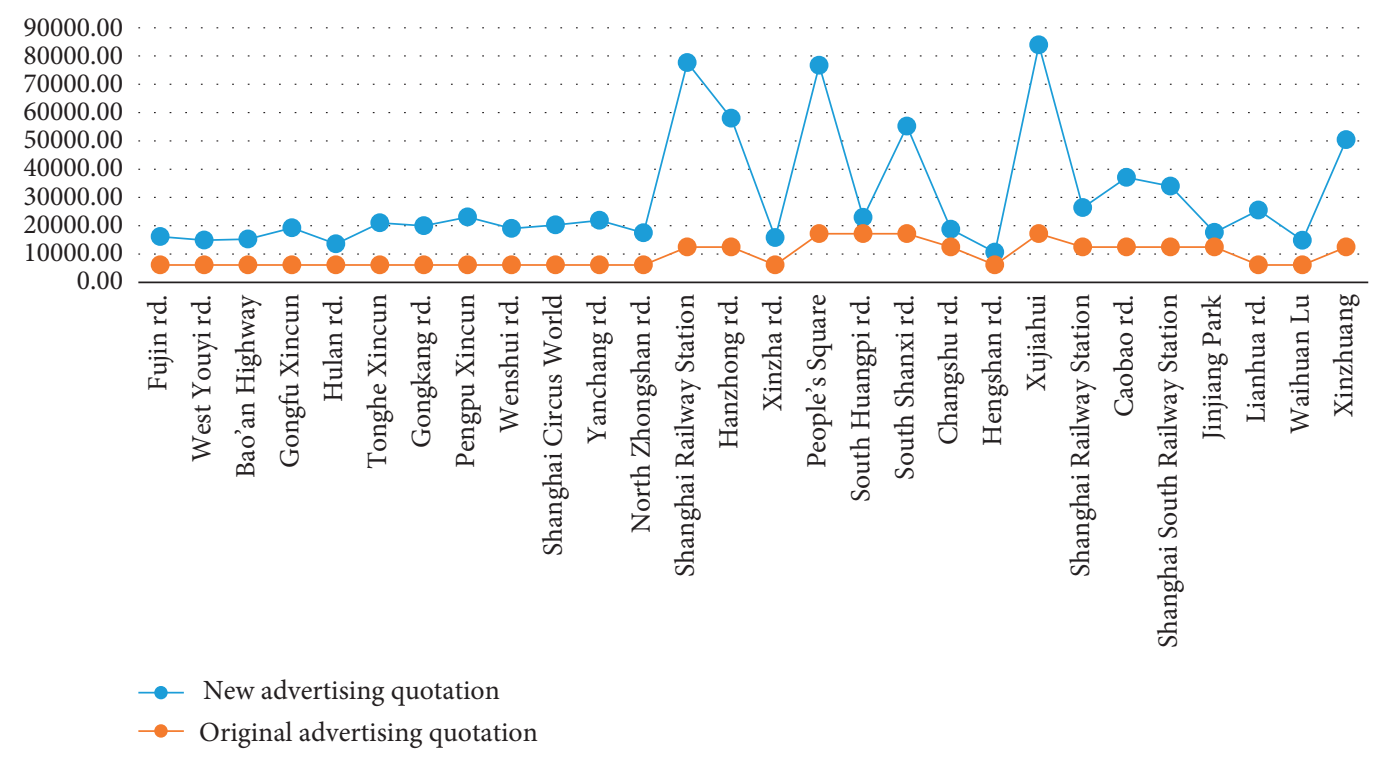

FIgURE 4: Comparison of the original and new advertising quotations. 


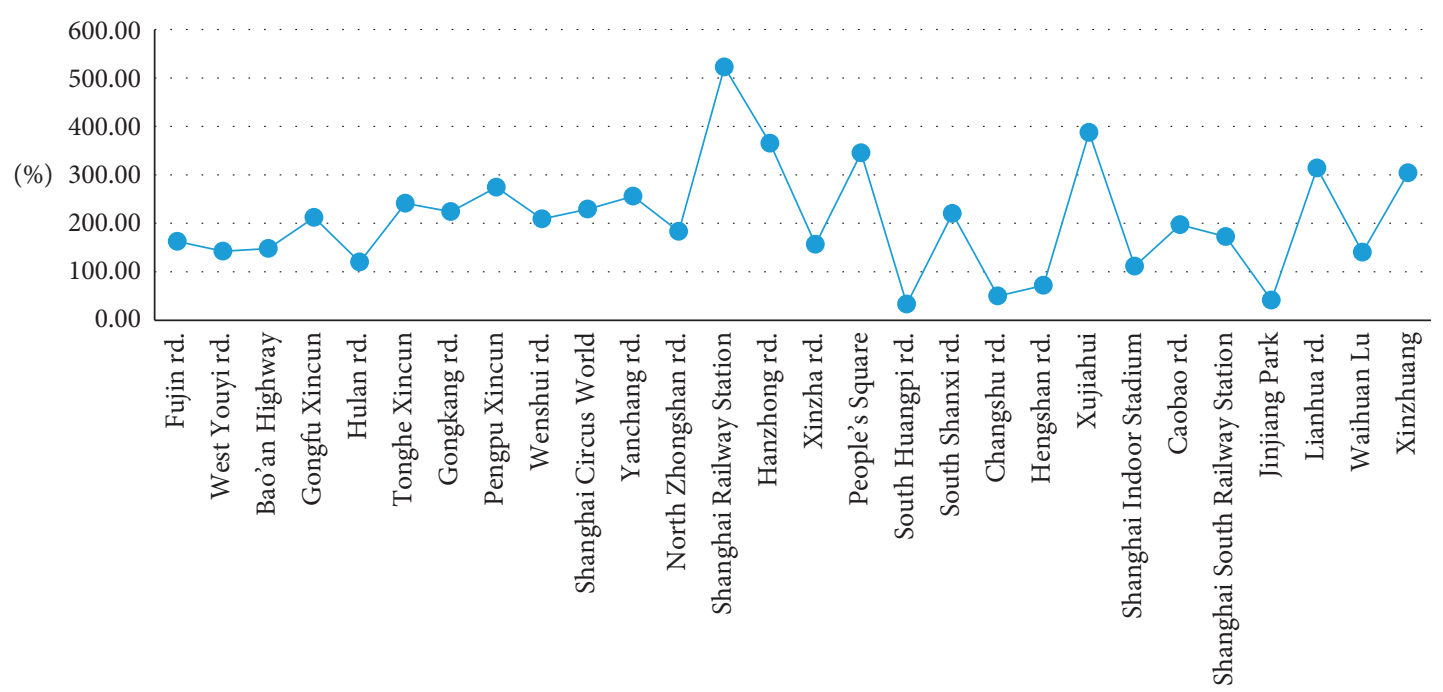

FIGURE 5: Advertising quotation growth rate between the original and new schemes.

TABLE 8: Quotation comparison of original and new advertising schemes.

\begin{tabular}{lcc}
\hline & Original advertising quotation & New advertising quotation \\
\hline One service day & 267208 & 846860 \\
\hline
\end{tabular}

TABLE 9: Advertising effect of the original advertising scheme.

\begin{tabular}{lc}
\hline & Original advertising scheme \\
\hline Proportion of passengers aged from 18 to 40 & $59.17 \%$ \\
Proportion of male passenger interested in healthy advertisement aged from 18 to 40 & $27.25 \%$ \\
Total passenger flow volume $(18 \mathrm{~h})$ & 175026 \\
Total effective passenger flow volume $(18 \mathrm{~h})$ & $175026 * 59.17 \% * 27.25 \%=28221$ \\
Total advertising quotation $(18 \mathrm{~h})$ & 267208 \\
Advertising effect (person/yuan/h) & $28221 / 267208 / 18=\mathbf{0 . 0 0 5 9}$ \\
\hline
\end{tabular}

TABle 10: Advertising effect of new advertising scheme.

\begin{tabular}{|c|c|c|c|c|c|}
\hline \multicolumn{6}{|c|}{ New advertising scheme } \\
\hline Station & $\begin{array}{l}\text { Time } \\
\text { period }\end{array}$ & $\begin{array}{c}\text { Total passenger flow } \\
\text { volume }(4.5 \mathrm{~h})\end{array}$ & $\begin{array}{l}\text { Total effective passenger flow volume } \\
(4.5 \mathrm{~h})\end{array}$ & $\begin{array}{l}\text { Total advertising } \\
\text { quotation }(4.5 \mathrm{~h})\end{array}$ & $\begin{array}{l}\text { Advertising effect } \\
\text { (person/yuan/h) }\end{array}$ \\
\hline \multirow{4}{*}{$\begin{array}{l}\text { Tonghe } \\
\text { Xincun }\end{array}$} & 1 & 2899 & 467 & 6648 & $\begin{array}{c}467 / 6648 / \\
4.5=0.0156\end{array}$ \\
\hline & 2 & 750 & 121 & 3512 & 0.0077 \\
\hline & 3 & 1883 & 304 & 5961 & 0.0113 \\
\hline & 4 & 1224 & 197 & 4883 & 0.0090 \\
\hline \multirow{2}{*}{ Yangchang rd. } & 1 & 2398 & 387 & 6396 & 0.0134 \\
\hline & 2 & 1244 & 201 & 4894 & 0.0091 \\
\hline \multirow{2}{*}{ Xinzha rd. } & 1 & 1162 & 187 & 4810 & 0.0087 \\
\hline & 3 & 1845 & 297 & 5924 & 0.0112 \\
\hline $\begin{array}{l}\text { South Shanxi } \\
\text { rd. }\end{array}$ & 1 & 1780 & 287 & 15501 & 0.0041 \\
\hline \multirow{3}{*}{ Changshu rd. } & 1 & 855 & 138 & 6858 & 0.0045 \\
\hline & 2 & 380 & 61 & 3307 & 0.0041 \\
\hline & 4 & 221 & 36 & 1954 & 0.0041 \\
\hline \multirow{4}{*}{ Caobao rd. } & 1 & 2020 & 326 & 12405 & 0.0058 \\
\hline & 2 & 936 & 151 & 7398 & 0.0045 \\
\hline & 3 & 1779 & 287 & 11740 & 0.0054 \\
\hline & 4 & 663 & 107 & 5493 & 0.0043 \\
\hline Average value & & & & & 0.0077 \\
\hline
\end{tabular}


however, some stations with low advertising grades had significantly larger daily passenger flow volume than stations with large high advertising grades. However, the current quotation does not display this advantage, making the pricing unreasonable. The neural networks training function allows the new quotation to address as many influencing factors as possible, eliminating the problems in the existing quotation scheme.

4.6. Application and Popularization. The analysis makes it clear that multiple variables influence subway advertising quotations and not just the station grade. Thus, it is important to consider the subway passengers' features, as well as the subway station itself. The neural networks scientifically links the subway advertising quotation with daily overall passenger flow volume, station transfer lines, and passengers' age structure. Meanwhile, the case study helps reveal that the original quotation and advertisement types are unreasonable. There are only 3 station grades; therefore, there are also only 3 grades of advertising quotations. However, the status quo has not been thoroughly considered, resulting in less profitability for stations with comparatively high daily overall passenger flow volumes. Furthermore, the existing advertising is in the form of a fulltime display model, resulting in unbalanced advertising profit. In terms of advertisement type, it is currently uncommon to involve an analysis of passengers' age structure in certain subway stations, thus diminishing the subway advertising effect.

To address these problems, this study developed a method for optimizing subway advertising using BP neural networks training. The core idea is to consider all the factors influencing subway advertising quotations, including passenger flow volume during a specific time period, the number of transfer lines in a station, the passengers' age structure, and the original advertising quotation. By researching the weights of these factors, this study gradually optimized the degree of fit between network predictions and reality. This ultimately provides a new target quotation, based on network trials to ensure the reasonableness of the quotation. Then, the analysis of the passengers' age structure helps identify the best advertisement types to cater to different passenger groups' preferences. Finally, after getting the new optimized advertising scheme and the recommended advertisement type for each subway stations during different time periods, the electronic advertising board is proposed to employ the new subway advertising scheme. By using the electronic advertising board, it is possible to alternate multiple advertisements within one board for different passenger groups in a whole service time, which considers the preferences of different passenger groups of each time period. As for the advertisers, they can choose the most suitable period (maybe one or two periods) for advertising in accordance with the new advertising scheme instead of the current single-track full-time advertising. This may not only reduce the advertising cost but also maximize effect of advertising. As for advertisement agencies, this kind of service will definitely increase their competitiveness.
Employing the time-of-use pricing system can make greater profits as a whole after the total quotation has increased, which is confirmed in the last subsection. Also, employing the recommended advertisement types will attract more advertisers and obtain some extra service fee.

This method can be applied to better understand subway advertising and may also be applied to optimize the advertising quotations and advertisement types at bus stations, the walls surrounding huge buildings, shopping malls, and other locations. In terms of shop locations, this method could also be applied to analyze passenger flow features in the area to aid in selecting the best location.

\section{Conclusion}

This paper studied the possible improvements in advertising profitability based on the transportation data of both shared bikes and subway systems. A new differentiated quotation scheme for subway advertising to increase profitability was proposed. The big data research helped estimate consumers' surplus. Using the electronic advertising board, it is possible to obtain the best advertising effect with lowest cost and increase profits for advertising agencies. To optimize price quotations, a neural networkbased function was developed. The main influencing factors included overall passenger flow volume at different subway stations at different time periods, the number of transfer lines of each station, the passengers' age structure at each station at different time periods ( 4 age brackets), and the existing subway advertising quotations. BP neural networks training automatically generates a "reasonable rule" between data input and output and automatically memorizes the content into the network value, to ensure the advertising quotation can reflect all the factors. The results show that all the optimized quotations were higher than the existing ones and varied among the stations. In this way, the network demonstrated all the factors' positive or negative influences on the quotations.

Shanghai Metro Line 1 was selected to implement the case study on optimizing subway advertising quotations. The method is worth popularizing, as the "globalization" of shared bikes means that this method can be applied with other metro lines and other advertising modes to make price quotations more reasonable and scientific. Finally, increasing the comprehensive profits from subway advertising can relieve the financial pressure on subway operations.

To close this paper, we review some minor limitations. This study is conducted based on the "shared bike plus subway" travel modes. For cities without shared bikes, this method might be difficult to be applied, mainly due to the lack of certain data. To make the ranking standard uniform, this study completed some conversions, possibly decreasing the accuracy. Also, the division of passenger age groups is limited to the raw data, which is why it may lose some characteristics, and may be improved in future studies. Despite of these aspects, this paper may help boost subway advertising stakeholders' profits and better regulate the subway advertising market to offer more reasonable quotations. 


\section{Data Availability}

The data used to support the findings of this study are available from the corresponding author upon request.

\section{Conflicts of Interest}

The authors declare that they have no conflicts of interest.

\section{Acknowledgments}

This study was supported by the Shanghai Philosophy and Social Science Planning Project under grant no. 2019ECK005 and the National Natural Science Foundation of China (NSFC) under grant no. 71701125.

\section{References}

[1] J. M. Butziger and G. Messina, "A new twist on an old technology: underground movies benefit public transportation," in Proceedings of the ASME/IEEE Joint Railroad Conference, pp. 87-94, Washington, DC, USA, April 2002.

[2] R. Mirsanei, S. Nateghi, and M. Jalalian, "Developing a new method for subway tunnel advertising," Optical Advertisement System, vol. 74, no. 1, pp. 21-32, 2012.

[3] M. Babar and F. Arif, "Smart urban planning using big data analytics to contend with the interoperability in internet of things," Future Generation Computer Systems, vol. 77, pp. 65-76, 2017.

[4] I. Cano, A. Tenyi, E. Vela, F. Miralles, and J. Roca, "Perspectives on big data applications of health information," Current Opinion in Systems Biology, vol. 3, pp. 36-42, 2017.

[5] R. Nachiappan, B. Javadi, R. N. Calheiros, and K. M. Matawie, "Cloud storage reliability for big data applications: a state of the art survey," Journal of Network and Computer Applications, vol. 97, no. 1, pp. 35-47, 2017.

[6] H. A. Hilal, "Neural networks applications for CDMA systems in non-Gaussian multi-path channels," AEU-International Journal of Electronics and Communications, vol. 73, pp. 150-156, 2017.

[7] D. E. Rumerlhar, G. E. Hinton, and R. J. Williams, "Learning representation by back-propagating errors," Nature, vol. 323, no. 6088, pp. 533-536, 1986.

[8] F. Frost and V. Karri, "Performance comparison of BP and GRNN models of the neural network paradigm using a practical industrial application," in Proceedings of the 6th International Conference on Neural Information Processing, vol. 3, pp. 1069-1074, Perth, Australia, November 1999.

[9] M. Yasser, H. Tanaka, and I. Mizumoto, "A method of simple adaptive control using neural networks with offset error reduction for an SISO magnetic levitation system," in Proceedings of the IEEE International Conference on Modelling, Identification Journal of Advanced Mechatronic Systems, vol. 3, pp. 191-196, Okayama, Japan, July 2010.

[10] C.-X. J. Feng, A. C. Gowrisankar, A. E. Smith, and Z.-G. S. Yu, "Practical guidelines for developing BP neural network models of measurement uncertainty data," Journal of Manufacturing Systems, vol. 25, no. 4, pp. 239-250, 2006.

[11] L. Grippo, "Unconstrained optimization in neural network training," in Encyclopedia of Optimization, Springer, Berlin, Germany, 2001.
[12] M. Mavrovouniotis and S. Yang, "Training neural networks with ant colony optimization algorithms for pattern classification," Soft Computing, vol. 19, no. 6, pp. 1511-1522, 2015.

[13] J. Eliasson, "A cost-benefit analysis of the Stockholm congestion charging system," Transportation Research Part A: Policy and Practice, vol. 43, no. 4, pp. 468-480, 2009.

[14] S. Sachan and N. Kishor, "Optimal location and optimum charging of electric vehicle based on sensitivity indices," in Proceedings of the IEEE Innovative Smart Grid Technologies-Asia (2015), pp. 1-6, Bangkok, Thailand, November 2015.

[15] Y. L. Yan, B. C. Chen, Y. G. Zhao, Y. Chen, X. B. Ma, and X. R. Kong, "Nonlinear inversion for electrical resistivity tomography," Chinese Journal of Geophysics, vol. 52, no. 3, pp. 758-764, 2009.

[16] J. Z. Yan, Z. B. Xu, Y. C. Yu, H. X. Xu, and K. L. Gao, "Application of a hybrid optimized BP network model to estimate water quality parameters of Beihai lake in Beijing," Applied Sciences-Basel, vol. 9, no. 9, pp. 1-13, 2019.

[17] R. Li, H. Zhang, N. Yu, R. Li, and Q. Zhuang, "A fast approximation for 1-D inversion of transient electromagnetic data by using a back propagation neural network and improved particle swarm optimization," Nonlinear Processes in Geophysics, vol. 26, no. 4, pp. 445-456, 2019.

[18] C. Y. Zhang, R. R. Zhang, Z. H. Dai, B. Y. He, and Y. Yao, "Prediction model for the water jet falling point in fire extinguishing based on a GA-BP neural network," Plos One, vol. 14, no. 9, Article ID e0221729, 2019.

[19] W. Han, L. B. Nan, M. Su, Y. Chen, R. N. Li, and X. J. Zhang, "Research on the prediction method of centrifugal pump performance based on a double hidden layer BP neural network," Energies, vol. 12, no. 14, pp. 1-14, 2019.

[20] DT Finance and Economics, "Data report on shared bike travel of $1 \mathrm{~km}$ of Shanghai Metro in 2017," 2017, http:// newsxmwb.xinmin.cn/chengsh/2017/12/01/31338637.html.

[21] Shanghai Urban and Rural Construction and Transportation Development Research Institute, Shanghai Comprehensive Transportation Annual Report, Shanghai Urban and Rural Construction and Transportation Development Research Institute, Shanghai, China, 2018, http://www.jtcx.sh.cn/ trafficanalyse.html. 